\title{
Bimodal Respiratory-Locomotor Neurons in the Neonatal Rat Spinal Cord
}

\author{
Jean-Patrick Le Gal, Laurent Juvin, Laura Cardoit, and Didier Morin \\ Institut de Neurosciences Cognitives et Intégratives d'Aquitaine, CNRS, UMR 5287, Université de Bordeaux, 33076 Bordeaux, France
}

Neural networks that can generate rhythmic motor output in the absence of sensory feedback, commonly called central pattern generators (CPGs), are involved in many vital functions such as locomotion or respiration. In certain circumstances, these neural networks must interact to produce coordinated motor behavior adapted to environmental constraints and to satisfy the basic needs of an organism. In this context, we recently reported the existence of an ascending excitatory influence from lumbar locomotor CPG circuitry to the medullary respiratory networks that is able to depolarize neurons of the parafacial respiratory group during fictive locomotion and to subsequently induce an increased respiratory rhythmicity (Le Gal et al., 2014b). Here, using an isolated in vitro brainstem-spinal cord preparation from neonatal rat in which the respiratory and the locomotor networks remain intact, we show that during fictive locomotion induced either pharmacologically or by sacrocaudal afferent stimulation, the activity of both thoracolumbar expiratory motoneurons and interneurons is rhythmically modulated with the locomotor activity. Completely absent in spinal inspiratory cells, this rhythmic pattern is highly correlated with the hindlimb ipsilateral flexor activities. Furthermore, silencing brainstem neural circuits by pharmacological manipulation revealed that this locomotor-related drive to expiratory motoneurons is solely dependent on propriospinal pathways. Together these data provide the first evidence in the newborn rat spinal cord for the existence of bimodal respiratory-locomotor motoneurons and interneurons onto which both central efferent expiratory and locomotor drives converge, presumably facilitating the coordination between the rhythmogenic networks responsible for two different motor functions.

Key words: brainstem-spinal cord preparation; locomotion; neural network interactions; newborn rat; respiration; thoracolumbar expiratory neurons

\section{Significance Statement}

In freely moving animals, distant regions of the brain and spinal cord controlling distinct motor acts must interact to produce the best adapted behavioral response to environmental constraints. In this context, it is well established that locomotion and respiration must to be tightly coordinated to reduce muscular interferences and facilitate breathing rate acceleration during exercise. Here, using electrophysiological recordings in an isolated in vitro brainstem-spinal cord preparation from neonatal rat, we report that the locomotor-related signal produced by the lumbar central pattern generator for locomotion selectively modulates the intracellular activity of spinal respiratory neurons engaged in expiration. Our results thus contribute to our understanding of the cellular bases for coordinating the rhythmic neural circuitry responsible for different behaviors.

\section{Introduction}

Functional interactions between neural networks constitute one of the basal requirements of the CNS. This allows the production

\footnotetext{
Received May 12, 2015; revised Nov. 12, 2015; accepted Dec. 4, 2015.

Author contributions: J.-P.L.G., L.J., and D.M. designed research; J.P.L.G., L.J., and L.C. performed research; J.-P.L.G. analyzed data; J.-P.L.G., L.J., and D.M. wrote the paper.

J.-P.L.G. was supported by a doctoral studentship from the French Ministère de l'Enseignement Supérieur et de la Recherche. We thank Etienne Guillaud for his skillful software programming for stimulation control, and John Simmers for his valuable comments on the manuscript and for English revision.

The authors declare no competing financial interests.

Correspondence should be addressed to Didier Morin, Institut de Neurosciences Cognitives et Intégratives d'Aquitaine (INCIA), CNRS UMR 5287, Université de Bordeaux, 146 rue Léo Saignat, Zone Nord, Bâtiment 2B, 33076 Bordeaux, France. E-mail: didier.morin@u-bordeaux.fr.
}

of a well adapted behavior needed to satisfy the demands imposed by both environment and organism. In this context, central pattern generators (CPGs) producing locomotion can control or modulate the activity of other neural networks engaged in otherwise separate rhythmic motor behaviors. For example, ascending efference copies of rhythmic locomotor output produced by the lumbar CPG have been found to project to thoracic spinal circuitry. In Xenopus froglets (Beyeler et al., 2008) and the newborn rat (Falgairolle and Cazalets, 2007), this locomotor-related signal 
appears to play an important role in coordinating back and limb muscles during locomotion, and thereby contributes to postural adjustments of the trunk musculature. Moreover, the lumbarderived ascending locomotor signal is also engaged in interlimb coordination as a result of asymmetrical interactions between lumbar and cervical locomotor CPG networks where the former is able to impose its own locomotor pattern on the latter (Juvin et al., 2005, 2012). Furthermore, such ascending copies of lumbar locomotor output can also assist distant neural generators involved in the production of different rhythmic motor behaviors, such as gaze control or respiration. In Xenopus tadpoles (Combes et al., 2008; Lambert et al., 2012) and juvenile frogs (von Uckermann et al., 2013), the locomotor efference copy signal can help to stabilize gaze during swimming by modulating activity in the brainstem extraocular motor nuclei. Recently, we reported (Le Gal et al., 2014b) that locomotor CPG-derived efference copies in the neonatal rat can also tonically excite some neural components of the medullary respiratory network, leading to an increased respiratory rhythmicity.

This direct influence from the locomotor generator to the respiratory network thus constitutes a neurogenic mechanism that somehow could permit an interaction between oscillatory neural elements involved in these two different motor functions. However, whether spinal respiratory neurons receive a lumbar locomotor drive during locomotion remains largely unexplored. Here, using an in vitro isolated brainstem-spinal cord preparation from neonatal rat, we assessed the activity of different pools of spinal respiratory neurons during activation of the lumbar locomotor network. During episodes of fictive locomotion, only thoracolumbar expiratory neurons were found to express rhythmic depolarizations of their membrane potential in time with ispsilateral lumbar locomotor bursting. This locomotor-related drive consists of dual phasic and tonic components that persist when the brainstem synaptic circuitry is pharmacologically silenced. This finding strongly supports the conclusion that the excitatory locomotor CPG influences on spinal expiratory neurons depends exclusively on multisegmental propriospinal pathways. We therefore report for the first time in neonatal rat spinal cord the existence of thoracolumbar bimodal neurons with the ability to display a spontaneous expiratory activity pattern and a clear locomotor-related behavior. Consequently, in freely moving animals, this bimodal activation of spinal neurons may assist in coordinating these two different behavioral acts to reduce the mechanical impact of locomotor movement on respiratory system pressures and air flows, and to facilitate an increased respiratory rhythmicity during exercise. Part of this work has been presented previously in abstract form (Le Gal et al., 2014a).

\section{Materials and Methods}

Newborn rat lines and care. All surgical and experimental procedures conformed to the guidelines of the European Communities Council Directive and the local ethics committee of the University of Bordeaux. The protocol was approved by the Committee on the Ethics of Animal Experiments of the University of Bordeaux (Permit \#5012031A). Experiments were performed on newborn Sprague Dawley rats (of either sex) that were obtained from females raised in the breeding facility of our laboratory.

In vitro brainstem-spinal cord preparations. In vitro experiments were performed on isolated preparations of the brainstem and spinal cord of 0 - to 2-d-old rats. After anesthesia by hypothermia, animals were decapitated and eviscerated. The skin and muscles were rapidly removed, and then preparations were placed in a $25 \mathrm{ml}$ chamber containing circulating (flow rate, $5-10 \mathrm{ml} / \mathrm{min}$ ) artificial CSF (aCSF; see composition below) maintained at $10^{\circ} \mathrm{C}$ throughout the dissection procedure. The dissection was continued under binocular microscopy to gently isolate the brainstem (transected at the rostral pons) and spinal cord with its ventral roots still attached. The preparation was then placed in a $10 \mathrm{ml}$ recording chamber and pinned down with its ventral surface upward. Ten to 12 pins were inserted through the meninges that surround the brainstem and spinal cord to ensure mechanical stability. Preparations were superfused continuously (flow rate, $3-5 \mathrm{ml} / \mathrm{min}$ ) with aCSF equilibrated with $95 \% \mathrm{O}_{2} / 5 \% \mathrm{CO}_{2}, \mathrm{pH} 7.4$, containing the following (in $\mathrm{mm}$ ): $100 \mathrm{NaCl}, 4$ $\mathrm{KCl}, 1.2 \mathrm{NaH}_{2} \mathrm{PO}_{4}, 2 \mathrm{CaCl}_{2}, 1.3 \mathrm{MgCl}_{2}, 25 \mathrm{NaHCO}_{3}$, and 30 D-glucose. The temperature of the superfusant aCSF was progressively raised to $22-25^{\circ} \mathrm{C}$ before recording procedures began. Due to the relatively low bath temperature (Murakoshi et al., 1985), the obvious absence of afferent feedback (particularly resulting from the bivagotomy; Cohen, 1979), and inputs from higher brain regions, the presence of the pons (especially A5 nuclei that tonically depress the respiratory rhythm generator; Hilaire et al., 1989), and an aCSF containing a low $\mathrm{K}^{+} /$high $\mathrm{Ca}^{2+}$ concentration (Ruangkittisakul et al., 2007; Panaitescu et al., 2010) that reduces neuronal excitability, the spontaneous respiratory-like rhythms produced in this type of reduced preparation were typically very slow, with average cycle frequencies usually ranging from one to three episodes of bursts per minute. However, these experimental conditions allowed simultaneous recordings of inspiratory- and expiratory-related motor activities to be conducted for >2-3 h (Giraudin et al., 2012; Le Gal et al., 2014b).

Electrophysiological recording and stimulation. Respiratory-related activity in spinal ventral roots was recorded with glass suction electrodes filled with aCSF solution. Signals were amplified $(10,000 \times)$ by differential AC amplifiers (low cutoff, $100 \mathrm{~Hz}$; high cutoff, $1 \mathrm{kHz}$; model 1700 , A-M Systems), digitized and acquired via a CED 1401 interface, stored on a computer, and analyzed using Spike2 software (Cambridge Electronic Design). In some experiments, sacrocaudal afferent stimulation was used to induce episodes of fictive locomotion. To this end, sacrocaudal dorsal roots were stimulated by low-frequency pulses ( 30 pulses, $1 \mathrm{~Hz}, 0.5-1 \mathrm{~V}$ ) or high-frequency pulses ( 20 pulses, $10 \mathrm{~Hz}, 0.5-1 \mathrm{~V}$ ) delivered via glass suction electrodes from a Master-8 stimulator (A.M.P.I.) controlled by software written in the laboratory. Respiratory motoneurons and interneurons in the spinal cord were impaled with sharp glass microelectrodes ( $2 \mathrm{M} \mathrm{K}$-acetate, $0.1 \%$ biocytin; $60-90 \mathrm{M} \Omega$ ). The intracellular signals were amplified (Axoclamp-2B, Molecular Devices), digitized (model 1401, CED), and visualized on a computer with acquisition software (Spike 2, CED). To identify the type of a recorded neuron, depolarizing current $(+0.5$ to $1 \mathrm{nA})$ was injected directly into the cell to generate action potentials. In the case of a motoneuron, these evoked impulses were recorded in the axon of the cell in an associated spinal ventral root.

Drug application. Pharmacological substances were bath applied from at least $30 \mathrm{~min}$ after the end of dissection. When required, the recording chamber was partitioned in two compartments with barriers of syringeejected Vaseline to permit differential exposure of selected spinal cord regions to pharmacological treatment. The watertightness of the partitions was systematically checked at the end of the experiment by verifying that methylene blue added to one side of the Vaseline bridge did not leak into the other side. Experiments in which leakage was observed were discarded. A mixture of $N$-methyl-D,L-aspartate (NMA; $15 \mu \mathrm{M}$; Sigma) and serotonin [5-hydroxytryptamine (5-HT); $15 \mu \mathrm{M}$; Sigma-Aldrich] was applied to lumbar segments to elicit prolonged and stable episodes of fictive locomotion. To determine the involvement of the supraspinal region in the studied mechanism, tetrodotoxin (TTX; 1 mM; SigmaAldrich) was applied to brainstem.

Histology. Following each experiment, the spinal cord was stained for the motoneuronal marker Islet. The tissue was fixed overnight at $4{ }^{\circ} \mathrm{C}$ in $4 \%$ paraformaldehyde in PBS $(0.1 \mathrm{M})$, and then rinsed twice in PBS and cryoprotected with $20 \%$ sucrose in PBS overnight. After the tissue was embedded in Tissue Tek and frozen to $-80^{\circ} \mathrm{C}$ with cooled isopentane, $30-\mu \mathrm{m}$-thick serial frontal sections were cut on a cryostat. Free-floating sections were rinsed in PBS three times (each rinse lasted $10 \mathrm{~min}$ ); saturated with PBS, Triton X-100 0.3\%, and BSA $1 \%$; and incubated with a mouse anti-Islet antibody (1:250; Developmental Studies Hybridoma Bank) overnight at room temperature (RT). The sections were then rinsed in PBS, exposed to goat anti-mouse Alexa Fluor 488 secondary antibodies for $1 \mathrm{~h}$ at RT, and mounted in VECTASHIELD Hard-Set 
A

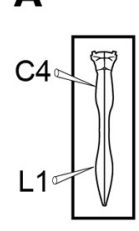

B1

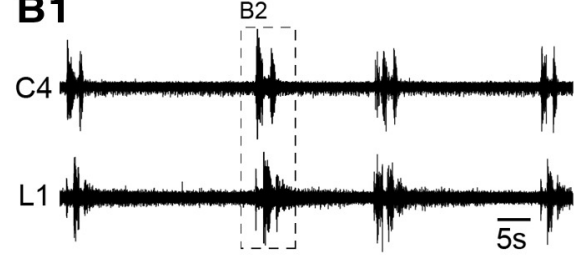

B2

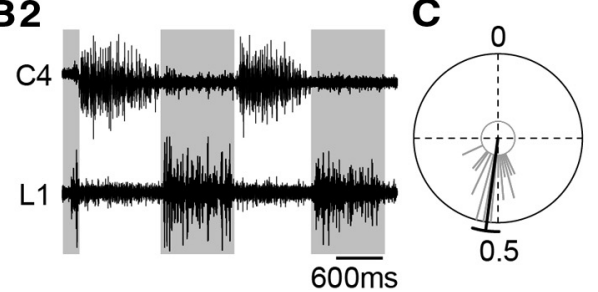

D

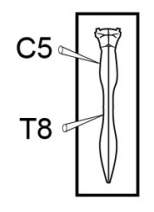

E2
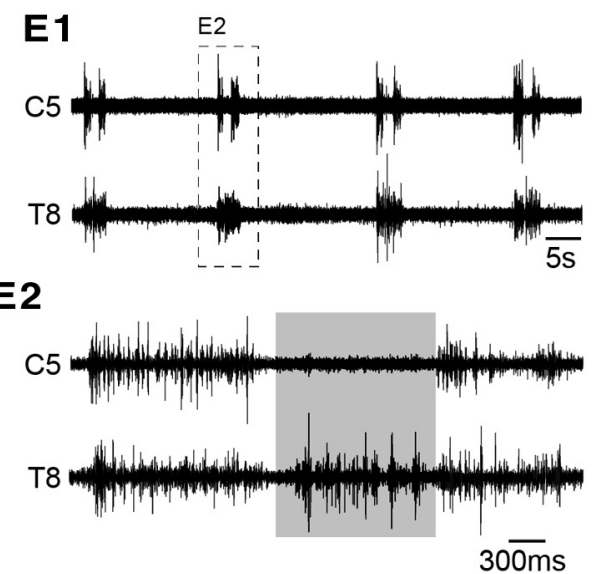

Figure 1. Pattern of spontaneous respiratory activity recorded in vitro from the isolated neonatal rat brainstem-spinal cord. $A, D$, Schematics of preparations with recording electrodes placed on cervical (C4 or C5), thoracic (T8), and lumbar (L1) spinal ventral roots. B1, E1, Different raw respiratory activities recorded in C4 or C5 (inspiratory-like), T8 (inspiratory- and expiratory-like), and L1 (expiratory-like) ventral roots. B2, E2, Expanded traces of respiratory bursts recorded in $C 4, C 5,78$, and L1 ventral roots. C, Circular plot of the phase relationship between $C 4$ inspiratory burst onset and L1 expiratory burst onset ( $n=22$ respiratory burst cycles).

Mounting Medium (Vector Laboratories). The biocytin contained in sharp glass microelectrodes used for recording neurons was revealed with FITC 568-conjugated extravidin (1:300; Sigma-Aldrich) in PBS solution for $1 \mathrm{~h}$ at RT. Processed preparations were mounted in VECTASHIELD Hard-Set, and fluorescence was visualized with a Leica SP5 confocal microscope. The images were color corrected and assembled with the Leica LAS AF Lite viewer and Adobe Photoshop.

Statistical analysis. The phase relationship between motor-related bursts (inspiratory vs expiratory, right vs left locomotor) in different ventral roots or individual motoneurons was determined by constructing a circular phase diagram (for details, see Juvin et al., 2012). Briefly, several bursts of a given motor output source were selected from a sequence of stable rhythmic activity and taken as the reference. The phase values of burst onsets in a second motor output were determined by dividing the latency (i.e., duration between consecutive burst onsets of each motor output) by the reference cycle period. The phase values were then plotted on a circular phase diagram with a scale ranging from 0 to 1 , where values close to 0.5 reflected burst alternation, whereas values approaching 0 or 1 indicated synchrony.

Statistical analyses were performed with SigmaPlot version 11.0 (Systat), and values were expressed as the mean \pm SEM. Student's $t$ test was used to compare the means of two groups, and repeated-measures ANOVA and Tukey's post hoc tests were used to compare more than two groups. Differences were considered statistically significant when the $p$ value was $<0.05$.

\section{Results}

Spatiotemporal distribution of spinal respiratory activities

Under control conditions, the respiratory motor activity generated by the isolated brainstem-spinal cord preparation (Fig. $1 A, D)$ consists of episodes of cyclic impulse bursts (mostly in doublets) occurring spontaneously in spinal ventral roots throughout the cervicolumbar cord (Fig. 1B1,E1). Due to our experimental conditions (lowered temperature, absence of sensory feedback, presence of pontine structures) and the saline $\mathrm{K}^{+} / \mathrm{Ca}^{2+}$ concentrations used (see Materials and Methods), the mean frequency of respiratory rhythms produced by these reduced preparations is generally low $(1.27 \pm 0.33$ burst episodes/ $\min ; n=8$ preparations). Despite this, motor activity recorded from the C4-C6 ventral roots, which contain axons of phrenic motoneurons, remains coincident with the discharge recorded extracellularly from the phrenic nerve (Morin et al., 2000) and movement of the thorax (Suzue, 1984), and is considered to closely reflect the inspiratory phase of respiration (Smith and
Feldman, 1987). Motor bursts recorded from L1-L2 ventral roots, which contain axons of abdominal motoneurons (Giraudin et al., 2008), are similar to the patterns of abdominal muscle activity recorded in vivo in the neonatal rat (Janczewski et al., 2002; Iizuka, 2009) and correspond to the expiratory phase (Smith et al., 1990; Iizuka, 1999, 2004; Ruangkittisakul et al., 2007). Contrary to what is observed in human and intact adult animals in which the discharge of abdominal muscles can occur in different patterns (augmenting, plateau, or decrementing) during the postinspiratory (early-expiratory) and preinspiratory (late-expiratory) periods (for review, see lizuka, 2011; Feldman et al., 2013), lumbar (abdominal) expiratory discharge occurs mainly during the first part of the expiratory phase (earlyexpiratory) when recorded in vitro in the neonatal rat spinal cord (Fig. 1B1). In most cases, it consists of a decrementing postinspiratory burst that can be associated with a short preinspiratory discharge (Fig. 1B2). It is noteworthy that during an episode of fictive respiration, the inspiratory-related and expiratory-related burst activities are generated alternately (Fig. 1B2), with a mean phase value of $0.52 \pm 0.06(n=22$ respiratory cycles; Fig. $1 C)$. It is also noteworthy that, in agreement with a previous study (Giraudin et al., 2008), thoracic T5-T12 respiratory outputs consist of both inspiratory and expiratory-related bursting (for example, see T8 ventral root; Fig. 1E2). Although some thoracic motoneurons can be recruited during both inspiratory and expiratory phases in the adult rat (de Almeida et al., 2010), the occurrence of temporally distinct motor discharges in a given motor root in our experiments is likely to reflect the alternating recruitment of external (inspiratory) and internal (expiratory) intercostal motor axons that are present within that ventral root (Saji and Miura, 1990). The isolated neonatal rat brainstem-spinal cord preparation is thus capable of generating spontaneous episodes of fictive respiration, which is expressed as inspiratory, mixed inspiratoryexpiratory, and expiratory motor outputs along the spinal cord.

\section{Spinal inspiratory neurons are not directly influenced by the locomotor generators}

Inspiratory neurons are distributed rostrocaudally within the cervicothoracic cord region, extending from C1 to T12 spinal segments (Giraudin et al., 2008). In a first step, we performed single-cell recordings of functionally identified interneurons and 
A

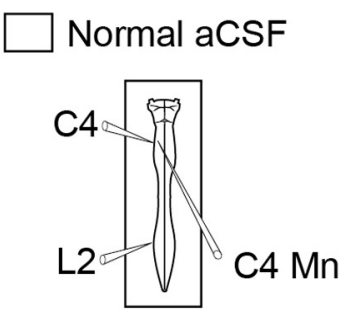

C1

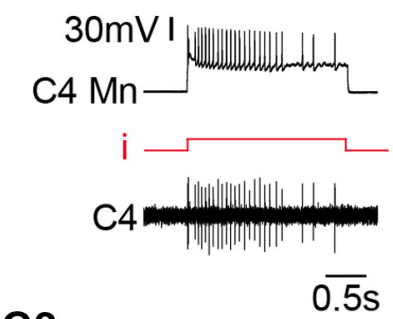

C2

$\overline{0.5 \mathrm{~s}}$

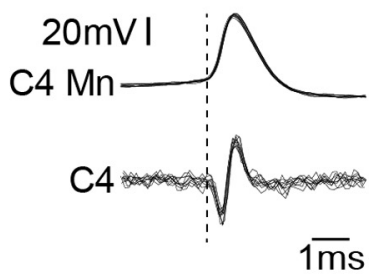

E

\section{Normal aCSF}

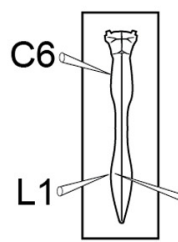

B1
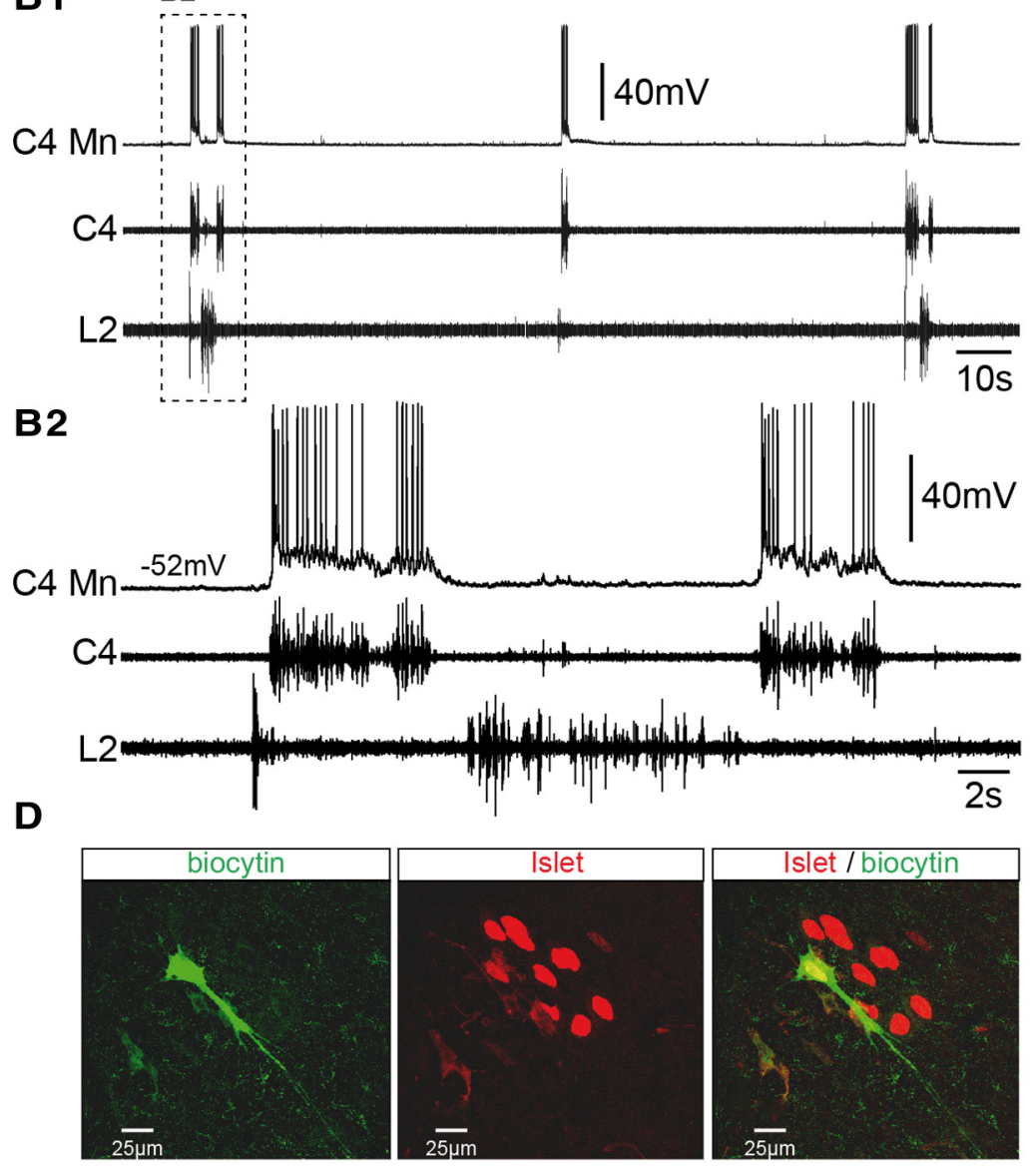

F1

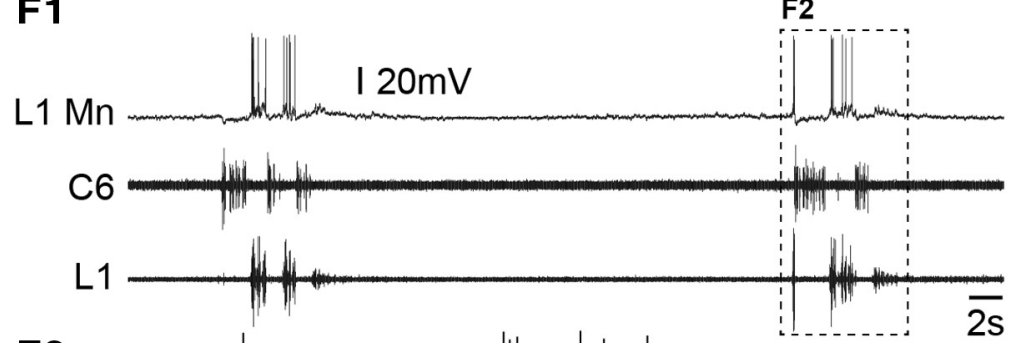

F2

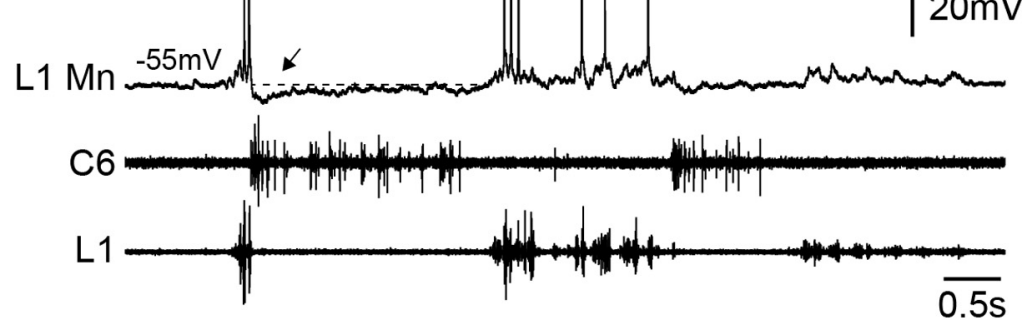

Figure 2. Functional identification of inspiratory and expiratory motoneurons. $A$, Schematic of the preparation with an intracellular electrode positioned on a cervical segment (C4) and extracellular recording electrodes placed on cervical (C4) and lumbar (L2) ventral roots. B1, B2, Spontaneous respiratory activity recorded in a cervical inspiratory motoneuron (C4 Mn), along with C4 (inspiratory-like) and L2 (expiratory-like) ventral roots. Expanded traces are shown in B2. C1, Orthodromic activation of a C4 inspiratory motoneuron (C4 Mn). Action potentials occurring 1:1 in a (4 root were evoked by depolarizing current injection (i; from 0.7 to $1.1 \mathrm{nA}$ ) into the motoneuron. C2, Superposition of 15 spikes generated by the $(4 \mathrm{Mn}$ and recorded in the corresponding $(4$ root. Note the constant delay between the onset of the central evoked action potential and that of the orthodromic axon spike in the $C 4$ ventral root. $\boldsymbol{D}$, Photomicrographs of immunolabeling for Islet (middle, red) in the biocytin-filled neuron (left, green) recorded in $\boldsymbol{B}$ and $\boldsymbol{C}$, and the merged image (right) confirming that the double-labeled (yellow) neuron was indeed a motoneuron. $\boldsymbol{E}$, Schematic of the preparation. Here, the intracellular electrode was positioned in lumbar segment (L1) and extracellular recording electrodes were placed on $(6$ and $\mathrm{L} 1$ ventral roots. F1, F2, Spontaneous respiratory activity recorded in a lumbar expiratory motoneuron (L1 Mn), and from C6 (inspiratory-like) and $\mathrm{L} 1$ (expiratory-like) ventral roots. Expanded traces are shown in $\boldsymbol{F}$. The dashed line indicates resting membrane potential. 


\begin{tabular}{|c|c|c|c|c|c|}
\hline Cell type & $\begin{array}{l}\text { RMP } \\
\text { (mV) }\end{array}$ & $\begin{array}{l}\mathrm{Rn} \\
(\mathrm{M} \Omega)^{a}\end{array}$ & $\begin{array}{l}\text { Vsyn } \\
(\mathrm{mV})^{b}\end{array}$ & $\begin{array}{l}\text { Fmax } \\
(\mathrm{Hz})^{c}\end{array}$ & $\begin{array}{l}\text { Burst } \\
\text { duration (s) }\end{array}$ \\
\hline \multicolumn{6}{|l|}{ Inspiratory } \\
\hline Cervical MN ( $n=7)$ & $-61 \pm 2$ & $42 \pm 10$ & $23 \pm 4$ & $61 \pm 10$ & $1.4 \pm 0.2$ \\
\hline Thoracic MN $(n=4)$ & $-54 \pm 6$ & $58 \pm 21$ & $10 \pm 5$ & $32 \pm 12$ & $1.1 \pm 0.4$ \\
\hline Pooled $(n=11)$ & $-58 \pm 3$ & $47 \pm 9$ & $18 \pm 3$ & $52 \pm 9$ & $1.6 \pm 0.2$ \\
\hline Cervical IN ( $n=10)$ & $-57 \pm 3$ & $71 \pm 17$ & $12 \pm 2$ & $43 \pm 9$ & $1.5 \pm 0.1$ \\
\hline Thoracic IN $(n=2)$ & $-58 \pm 9$ & 79 & $8 \pm 4$ & $31 \pm 5$ & $1.3 \pm 0.3$ \\
\hline Pooled $(n=12)$ & $-57 \pm 2$ & $72 \pm 14$ & $11 \pm 2$ & $41 \pm 7$ & $1.4 \pm 0.1$ \\
\hline \multicolumn{6}{|l|}{ Expiratory } \\
\hline Thoracic MN $(n=7)$ & $-58 \pm 3$ & $32 \pm 9$ & $7 \pm 1$ & $16 \pm 2$ & $1.4 \pm 0.2$ \\
\hline Lumbar MN $(n=11)$ & $-57 \pm 2$ & $48 \pm 10$ & $7 \pm 0.5$ & $14 \pm 3$ & $1.7 \pm 0.2$ \\
\hline Pooled $(n=18)$ & $-57 \pm 1$ & $41 \pm 7$ & $7 \pm 1$ & $14 \pm 2$ & $1.6 \pm 0.1$ \\
\hline Thoracic IN $(n=8)$ & $-63 \pm 2$ & $77 \pm 21$ & $6 \pm 1$ & $13 \pm 2$ & $2.0 \pm 0.3$ \\
\hline Lumbar IN $(n=7)$ & $-62 \pm 2$ & $64 \pm 11$ & $10 \pm 1$ & $14 \pm 3$ & $1.7 \pm 0.2$ \\
\hline Pooled $(n=15)$ & $-63 \pm 2$ & $69 \pm 10$ & $8 \pm 1$ & $13 \pm 2$ & $1.9 \pm 0.2$ \\
\hline
\end{tabular}

MN, Motoneuron; IN, interneuron; RMP, resting membrane potential; Rn, neuron input resistance; Vsyn, respiratory synaptic drive potential; Fmax, maximal firing frequency during respiratory synaptic drive.

${ }^{a} p<0.05$, comparison of pooled values.

${ }^{b} p<0.001$, comparison of pooled values.

${ }^{c} p<0.001$, comparison of pooled values.

motoneurons to examine membrane and firing properties of the four different types of cervical (C4-C8) and thoracic (T1-T10) inspiratory neurons. Intracellular recordings were obtained from 23 inspiratory neurons identified as interneurons ( $n=10$ cervical; $n=2$ thoracic) or motoneurons ( $n=7$ cervical; $n=4$ thoracic) on the basis of the outcome of their antidromic or orthodromic activation (Fig. 2C1,C2) and their immunoreactivity to Islet (Fig. 2D). All the reported neurons were spontaneously and rhythmically active during fictive respiration (Fig. 2B1), showing a large depolarization (motoneurons, $18 \pm 3 \mathrm{mV}, n=$ 11 ; interneurons, $11 \pm 2 \mathrm{mV}, n=12$ ) with associated spiking in phase with inspiratory-related $\mathrm{C} 4$ ventral root activity (Fig. 2B2), and therefore were classified as inspiratory cells. Details of passive membrane properties, spontaneous firing frequencies during depolarizing synaptic drives, and amplitudes of the central inspiratory drive potential of the four neuronal groups are given in Table 1. Because statistical analysis of these data did not reveal any significant differences either between cervical and thoracic motoneurons or between cervical and thoracic interneurons, we considered these two groups of inspiratory neurons as homogeneous cell populations (Table 1, pooled data).

We previously reported that, when active, the lumbar locomotor generators exert an excitatory ascending influence on the medullary respiratory rhythm network, leading to a significant increase in respiratory rhythm frequency (Morin and Viala, 2002; Le Gal et al., 2014b). To determine whether this ascending drive also directly modulates the spontaneous activity of spinal respiratory neural populations, single-unit recordings of cervicothoracic inspiratory neurons were performed before (Fig. $3 A, B$ ) and during coactivation of the lumbar locomotor networks. To elicit prolonged fictive locomotion, a mixture of NMA $(15 \mu \mathrm{M})$ and 5-HT $(15 \mu \mathrm{M})$ was selectively bath applied to the lumbosacral cord region (Fig. $3 C)$. In the presence of these neuromodulators, extracellular recordings from right and left L2 ventral roots, which primarily innervate hindlimb flexor muscles (Kjaerulff and Kiehn, 1996), showed robust coordinated rhythmic locomotor activity (Fig. 3D1) characterized by a strict left-right alternation (mean phase, $0.45 \pm 0.02 ; n=32$ random locomotor cycles; Fig. 3D3). During such episodes of drug-induced fictive loco- motion, all cervicothoracic inspiratory neurons retained their phasic inspiratory-related pattern of discharge (Fig. 3D1), and, in agreement with our previously reported data (Le Gal et al., 2014b), the respiratory rhythm frequency was significantly increased (from $1.27 \pm 0.33$ to $1.94 \pm 0.29$ burst episodes/ $\min ; p<0.001 ; n=8$ preparations). Although an ascending efference copy signal produced by the lumbar CPGs can clearly modulate the ongoing respiratory rate, no locomotorrelated change in the membrane potential of recorded cervicothoracic inspiratory motoneurons $(n=10$; Fig. $3 D 1, D 2)$ or interneurons $(n=10)$ was observed. Finally, it is noteworthy that similar results were obtained when fictive locomotion was elicited by electrical stimulation of sacrocaudal afferent pathways instead of by pharmacological activation (Table 2). All these results therefore support the conclusion that the lumbar locomotor networks do not directly influence cervicothoracic inspiratory neurons during fictive locomotion.

\section{Spinal expiratory neurons are directly influenced by the locomotor generators}

In a similar series of experiments, we recorded the activity of functionally identified expiratory neurons to assess their behavior during activation of lumbar locomotor generators. As previously mentioned, expiratory-related activity occurs in alternation with inspiration, and can be expressed spontaneously in motor roots from thoracic (T5) to lumbar (L2) segments (Giraudin et al., 2008). Intracellular recordings of 33 spinal expiratory neurons were made within the thoracic (T7T12) and lumbar (L1-L2) regions (Fig. 2E,F). On the basis of orthodromic activation and immunoreactivity to Islet, 18 cells ( $n=7$ thoracic; $n=11$ lumbar) were unambiguously identified as motoneurons, and the remaining 15 spinal expiratory cells were classified as interneurons. All expiratory neurons displayed spontaneous rhythmic membrane depolarizations that occurred in phase with lumbar expiratory motor output (Fig. 2F1), and were characterized by the presence of preinspiratory and postinspiratory spike discharges (Fig. 2F2). It is noteworthy that, at the onset of an inspiratory burst, expiratory motoneurons and interneurons hyperpolarized sharply by $-5.0 \pm 0.6 \mathrm{mV}(n=18)$, and $-4.4 \pm 0.6 \mathrm{mV}(n=11)$, respectively (Fig. 2F2, arrow), and depolarized when cervical activity ceased. Here again, details of passive membrane properties, firing frequencies during synaptic motor commands, and amplitudes of the central expiratory drive potential for the four neuronal groups are given in Table 1. Here also, due to a lack of significant differences in their passive and synaptic membrane properties, thoracolumbar expiratory motoneurons and interneurons were each considered as homogeneous cell populations (Table 1, pooled data). Finally, comparisons between inspiratory-related and expiratory-related cell groups revealed that the amplitude of the central inspiratory synaptic drive was significantly greater than that of the expiratory drive, resulting in a higher mean maximal firing frequency of inspiratory neurons (Table 1).

Again, to further explore the behavior of spinal respiratory neurons during fictive locomotion, intracellular recordings of expiratory cells were performed before (Fig. $4 A, B$ ) and during (Fig. $4 C, D$ ) activation of the lumbar locomotor generators. The lumbar spinal cord was selectively exposed to NMA/5-HT to activate locomotor patterns characterized by a clear left-right alternating bursting activity in bilateral L2 ventral roots (Fig. 4D1-D4), while the thoracocervical cord and brainstem were continuously superfused with normal saline solution. In these 
A

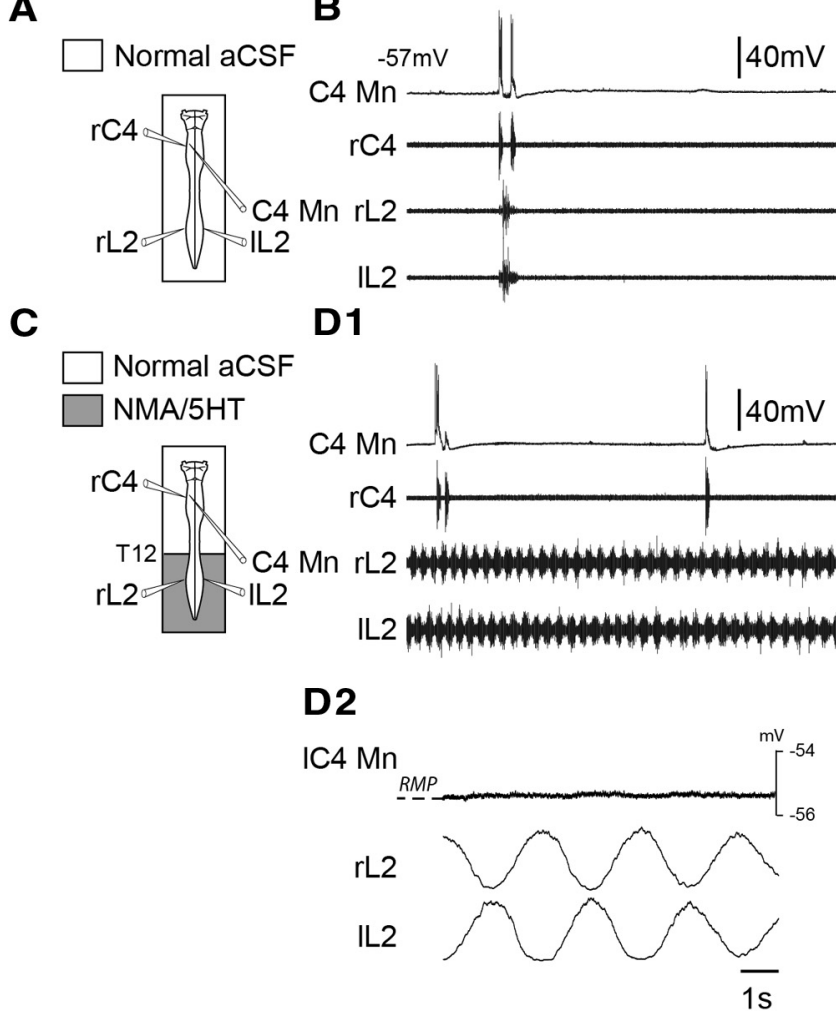

Figure 3. Absence of lumbar locomotor generator influence on inspiratory motoneurons during pharmacologically induced fictive locomotion. $A, C$, Schematics of the experimental procedures. $B, D 1$, Spontaneous activity of a $C 4$ inspiratory motoneuron (C4 Mn), and in C4 (inspiratory-like) and bilateral L2 (expiratory-like) ventral roots under control saline conditions (B) and during NMA/5-HT application to the lumbar cord region (D1). D2, Averaging of instantaneous membrane potential level of a $C 4$ inspiratory motoneuron and integrated left $(I)$ and right $(r) L 2$ root activity during 32 cycles of fictive locomotion. D3, Circular plot illustrating the phase relationship between the onsets of integrated motor bursts recorded over 32 random cycles from left (I) and right (r) L2 ventral roots. RMP, Resting membrane potential.

that a large number of recorded thoracic motoneurons (five of five motoneurons) and interneurons (two of four interneurons) displayed both locomotor- and expiratory-related drives (Fig. $4 D$ ), and two interneurons (2 of 4 interneurons) displayed only a locomotor-related drive. Furthermore, in a certain number of cases (two of five motoneurons; three of four interneurons), the strength of the locomotor-related drive was sufficient to reach spike threshold and the production of impulse bursting.

Because populations of lumbar expiratory motoneurons (Fig. $5 A-D$ ) and interneurons (Fig. $5 E-I$ ) are located in the immediate vicinity of the hindlimb locomotor networks, drug-induced locomotion was no longer used because of a concomitant pharmacological activation of lumbar respiratory neurons. For this reason, repetitive electrical stimulation of sacrocaudal dorsal root afferents was used as an alternative drug-free method for lumbar locomotor network activation (Lev-Tov et al., 2000; Whelan et al., 2000; Etlin et al., 2013). Similar to thoracic expiratory cells during pharmacological activation of the lumbar cord, all lumbar expiratory motoneurons (Fig. 5C,D1) and interneurons (Fig. 5E,F1) displayed rhythmic locomotor-like oscillations of their membrane potential during afferent stimulusevoked fictive locomotion (Table 2). Here again, the locomotor drive recorded from the lumbar neurons consisted of repetitive oscillations [motoneurons, $4.66 \pm 0.85$

Table 2. Impact of pharmacologically or electrically evoked fictive locomotion on the membrane potential of spinal inspiratory and expiratory neurons

\begin{tabular}{|c|c|c|c|c|c|}
\hline \multirow[b]{2}{*}{ Cell type } & \multirow[b]{2}{*}{ N } & \multicolumn{3}{|c|}{ Number of neurons tested } & \multirow{2}{*}{$\begin{array}{l}\text { Locomotion-induced } \\
\text { membrane } \\
\text { oscillations }\end{array}$} \\
\hline & & $\begin{array}{l}\mathrm{NMA} / 5 \mathrm{HT} \\
\text { only }\end{array}$ & $\begin{array}{l}\text { SCA stimulation } \\
\text { only }\end{array}$ & Both & \\
\hline \multicolumn{6}{|l|}{ Inspiratory } \\
\hline Cervical MN & 7 & 3 & & 4 & $0 / 7$ \\
\hline Thoracic MN & 3 & 1 & 1 & 1 & $0 / 3$ \\
\hline Cervical IN & 9 & 4 & 4 & 1 & $0 / 9$ \\
\hline Thoracic IN & 1 & & 1 & & $0 / 1$ \\
\hline \multicolumn{6}{|l|}{ Expiratory } \\
\hline Thoracic MN & 6 & 2 & 1 & 3 & $6 / 6$ \\
\hline Lumbar MN & 8 & & 8 & & $8 / 8$ \\
\hline Thoracic IN & 4 & 1 & & 3 & $4 / 4$ \\
\hline Lumbar IN & 7 & & 7 & & $7 / 7$ \\
\hline
\end{tabular}

MN, motoneuron; IN, interneuron; SCA, sacrocaudal afferent.

experimental conditions, all thoracic expiratory motoneurons and interneurons (Table 2) showed rhythmic depolarizations of their membrane potential (Fig. 4D1-D3) that occurred in phase with ipsilateral L2 locomotor bursts (mean phase value, $0.05 \pm$ $0.01 ; n=65$ locomotor cycles; Fig. 4D4). A closer inspection of this rhythmic central locomotor drive revealed the presence of a dual-component influence (Fig. 4D2,D3) consisting of phasic membrane potential oscillations (motoneurons, $3.86 \pm 0.36 \mathrm{mV}, n=5$; interneurons, $4.18 \pm 0.39 \mathrm{mV}, n=4)$ superimposed on a tonic depolarization (motoneurons, $3.77 \pm 0.58 \mathrm{mV}, n=5$; interneurons, $5.34 \pm 1.97 \mathrm{mV}, n=4)$. Under these conditions, it is noteworthy
$\mathrm{mV}, n=8$ (Fig. 5D2); interneurons, $5.56 \pm 1.82 \mathrm{mV}, n=7$ (Fig. $5 F 2)]$ that occurred in phase with ispsilateral L1 locomotor bursts [motoneurons: mean phase value, $0.09 \pm 0.05, n=31$ locomotor cycles (Fig. $5 G$, middle); interneurons: mean phase value, $0.07 \pm$ $0.02, n=27$ locomotor cycles (Fig. 5G, right)], and superimposed on a tonic membrane depolarization (motoneurons: $3.62 \pm 0.69 \mathrm{mV}, n=8$; interneurons: $2.59 \pm 1.05 \mathrm{mV}, n=7$ ). Regardless of the mode of activation of spinal locomotor networks (by chemical or afferent electrical stimulation), the amplitude of tonic and phasic depolarizations in lumbar and thoracic expiratory neurons showed no significant differences (tonic component in lumbar vs thoracic neurons, $p=0.67$; phasic component, $p=0.76$ ). Similar to what we observed in thoracic spinal neurons, a large number of lumbar motoneurons (six of eight motoneurons) and interneurons (five of seven interneurons) continued to express both locomotor- and expiratory-like oscillatory activity (Fig. 5F2, arrow), and, for some of them (two of eight motoneurons; four of seven interneurons), the amplitude of the locomotor-related command was sufficient to attain spike threshold and impulse bursting to be generated (Fig. 5D1,F1).

Finally, to rule out the possibility that these rhythmic potential oscillations were somehow due to a simple reflex activating process, without the involvement of central rhythmogenic circuitry, the duration of sacrocaudal afferent stimulation was shortened (to $2 \mathrm{~s}$ ), and the frequency of stimulation increased (from 1 to $10 \mathrm{~Hz}$ ). This allowed the lumbar locomotor generators to be activated by a briefer triggering 
stimulus without the continual recruitment of spinal sensorimotor loops that might occur during tonic activating stimulation. In these conditions, locomotor-like burst discharge continued to be expressed in bilateral lumbar L1 motor roots after the short episode of sacrocaudal dorsal root stimulation had ceased (Fig. 5I1). Significantly, also during this persistent poststimulus bursting, lumbar expiratory motoneurons and interneurons (Fig. 5I2) continued to express locomotor-like oscillatory activity that was in phase with ipsilateral L1 ventral root bursts. Together, therefore, these results support the conclusion that the lumbar locomotor generators rhythmically modulate the membrane potential of thoracolumbar expiratory neurons.

Pathways mediating the locomotor drive to spinal expiratory neurons

We reported previously that efferent copies from the lumbar locomotor networks are conveyed by long projection pathways to the brainstem respiratory networks where they increase the ongoing respiratory rate (Le Gal et al., 2014b). Is the rhythmic modulation of spinal expiratory neurons during locomotion mediated by a supraspinal relay involving these ascending pathways or is it dependent on local direct pathways within the spinal cord? To address this question, a final series of in vitro experiments $(n=4)$ was conducted in which all supraspinal activity was silenced by pharmacological manipulation. As described above in control conditions, lumbar respiratory neurons spontaneously expressed rhythmic depolarizations in phase with the expiratory-related burst discharges recorded from L1 ventral roots (Fig. 6A,B). Again, during sacrocaudal afferent-evoked fictive locomotion, such lumbar expiratory neurons generated rhythmic oscillations that were tightly correlated with locomotor activity recorded in the ipsilateral L1 ventral root (Fig. 6C,D). Following this functional characterization, the voltage-gated sodium channel blocker TTX $(0.5 \mu \mathrm{M})$ was selectively applied to the brainstem region to completely suppress pontomedullary circuit activity (Fig. 6E), while the entire spinal cord continued to be superfused with normal saline solution. After TTX treatment and with respiratory rhythmicity absent (Fig. $6 F$ ), sacrocaudal dorsal root afferent stimulation (Fig. $6 G$ ) conserved its ability to activate the lumbar locomotor generators, which in turn produced unaffected episodes of locomotor burst activity in lumbar L1 motor outputs (Fig. $6 \mathrm{H}$ ). Importantly furthermore, during such bouts of afferent-evoked fictive locomotion in the enforced absence of fictive respiration, locomotor-timed rhythmic oscillations were still observed in lumbar expiratory neurons (Fig. 6H), and showed no significant differences from the locomotor drive generated in control conditions. We therefore conclude that the excitatory influence of the hindlimb locomotor generators on spinal expiratory neurons relies exclusively on local propriospinal pathways.

\section{Discussion}

\section{Bimodal respiratory-locomotor spinal neurons}

Previous evidence from a variety of studies has suggested that the lumbar rhythm generators for locomotion may interact with spinal respiratory circuitry to modulate, or to control, motor efferent activity in several respiratory muscles. For example, in curarized spinal rabbits treated with a mixture of nialamide and DOPA, locomotor-like phrenic bursting activity generated by the cervical cord can be driven by lumbar locomotor neural circuitry (Viala et al., 1979; Viala, 1986) in a pattern that is strongly correlated with the hindlimb extensor-type activities (Viala et al., 1987). Similarly in spinalized and paralyzed cats, the pharmacological activation of locomotor generators results in alternating rhythmic activity between the left and right phrenic nerves (Schomburg et al., 2003). Here again, this predominant pattern of phrenic motor output, which could serve as a trunk-stabilizing mechanism, is clearly coupled to the fictive locomotor rhythm, even though different phase relationships could be observed (Schomburg et al., 2003). On the basis of these findings, it was postulated that, during locomotion, the lumbar rhythm generators also project an efference copy signal to spinal inspiratory neurons. Somewhat surprisingly in our experiments, a locomotor-related influence was never observed in cervical (phrenic) and thoracic (intercostal) inspiratory motoneurons and interneurons during episodes of fictive locomotion. This dis- 
A

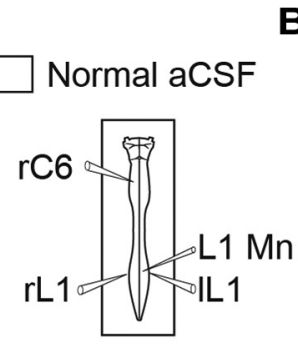

C

$\square$ Normal aCSF

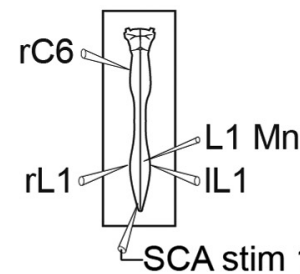

E

$\square$ Normal aCSF

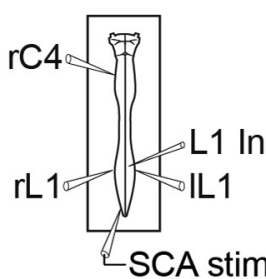

B

\section{D1}

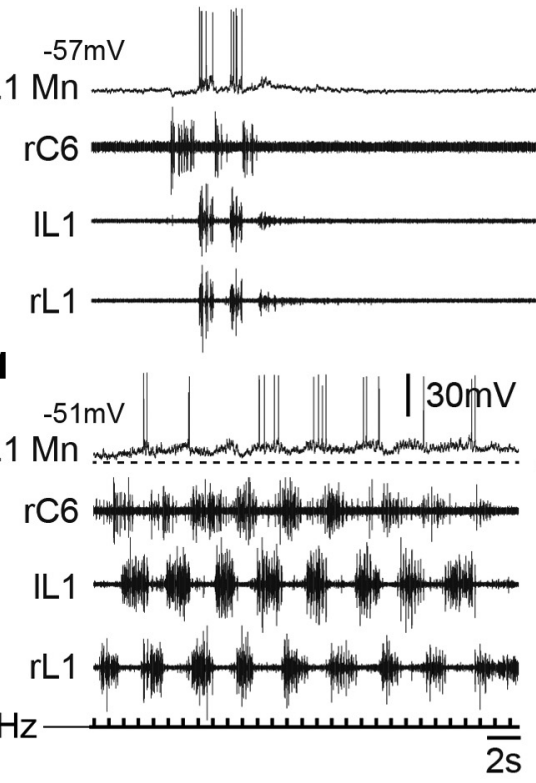

F1

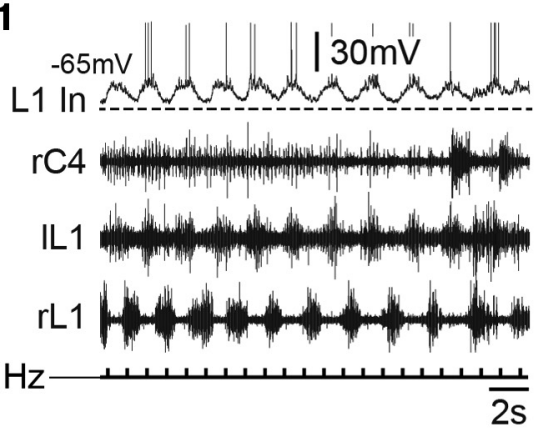

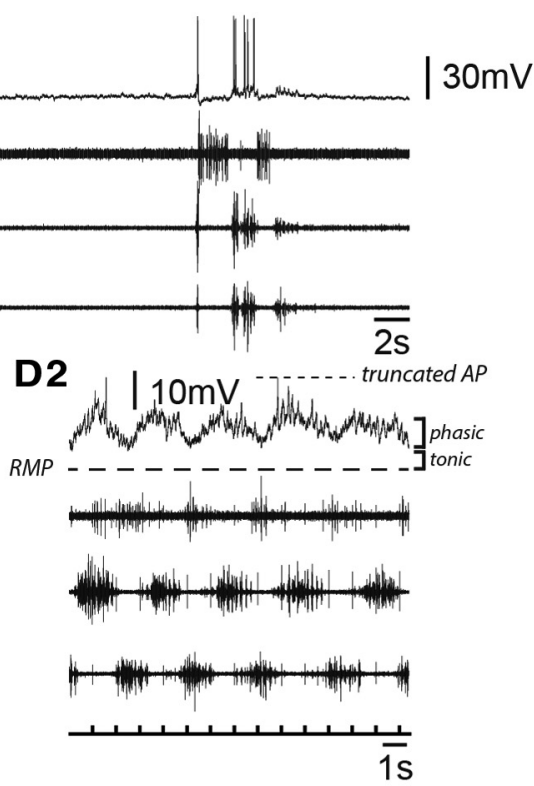

F2
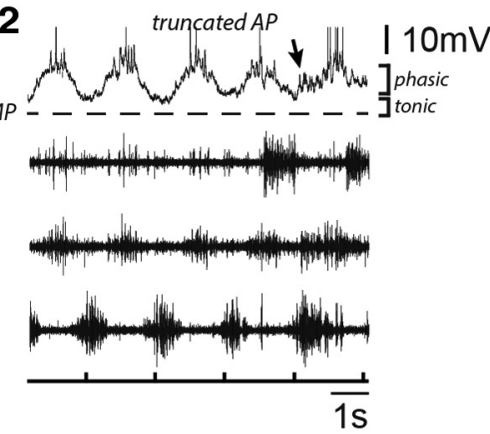

G

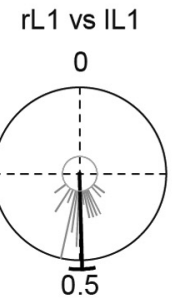

L1 Mn vs IL1

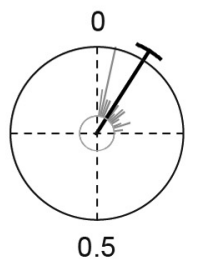

L1 In vs IL1

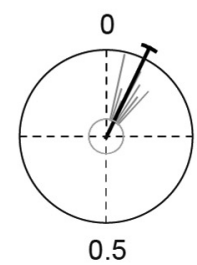

H

11

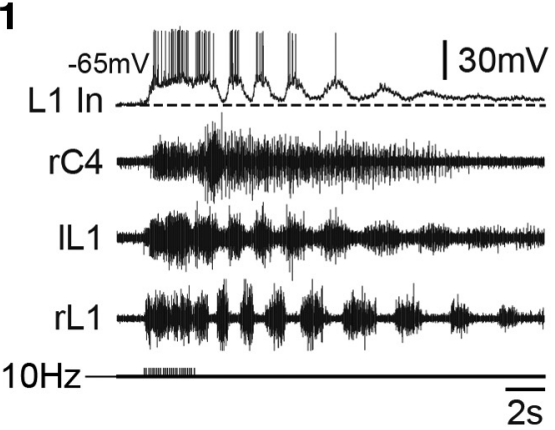

12

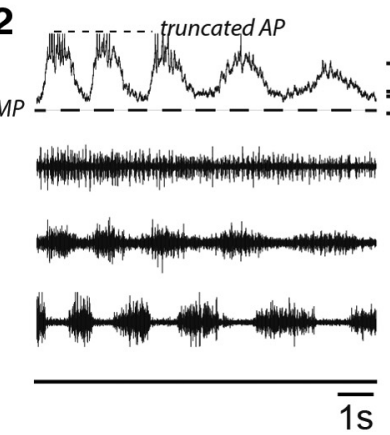

Figure 5. Lumbar expiratory motoneurons and interneurons are rhythmically driven during fictive locomotion elicited by sacrocaudal afferent electrical stimulation. $\boldsymbol{A}, \boldsymbol{C}, \boldsymbol{E}, \boldsymbol{H}$, Schematics of the experimental procedures. $\boldsymbol{B}, \mathbf{D 1}, \mathbf{D 2}$, Rhythmic activity of a lumbar expiratory motoneuron (L1 Mn), and in C6 (inspiratory-like) and left (I) and right (r) L1 (expiratory-like) ventral roots under control saline conditions $(\boldsymbol{B})$, and during continuous repetitive electrical stimulation (30 pulses, $1 \mathrm{~Hz}, 0.5-1 \mathrm{~V}$; D1) of sacrocaudal dorsal root afferents (SCA stim). Corresponding expanded traces are shown in $\mathbf{D 2}$. F1, $\mathbf{F 2}, \mathbf{I 1}, \mathbf{I 2}$, Rhythmic activity recorded in a lumbar expiratory interneuron (L1 In), and in C4 (inspiratory-like) and left (I) and right (r) L1 (expiratory-like) ventral roots during continuous (30 pulses, $1 \mathrm{~Hz}, 0.5-1 \mathrm{~V} ; \boldsymbol{F}$ ) or train (20 pulses, $10 \mathrm{~Hz}, 0.5-1 \mathrm{~V}$; I1) electrical stimulation of SCA stim. Corresponding expanded traces are shown in $\mathbf{F} \mathbf{2}$ and $\mathbf{I} \mathbf{2}$. The arrow in $\mathbf{F}$ indicates the expiratory-related drive received by the interneuron during the locomotor episode. $\mathbf{G}$, Circular plots showing the phase relationships between integrated motor bursts recorded in right and left L1 ventral roots (plot at left), and between the onsets of locomotor-related membrane depolarizations in the L1 Mn (plot at middle) or L1 In (plot at right) and integrated motor bursts ( $n=31$ ) recorded in the ipsilateral (I, left) L1 ventral root (plot at left). AP, Action potential; RMP, resting membrane potential. 
similarity could result from a combination of factors, including interspecies differences (rabbit/cat vs rat), experimental approaches (in vivo vs in vitro), and stage of development (adult vs neonate). Moreover, it is noteworthy that in the earlier adult animal experiments (Viala et al., 1979; Schomburg et al., 2003), fictive locomotion was induced by intravenous injection of nialamide/DOPA, whereas in our in vitro study, locomotor rhythmogenesis was evoked by the selective bath application of NMA/5HT to the lumbosacral cord. While the widespread diffusion of intravenously injected drugs may nonspecifically change neuronal excitability throughout the spinal cord, the local application of neuroactive drugs that we used in our split-bath experiments avoided the presence of any exogenous chemicals in the rostral cord region. Consequently, the neuromodulatory environment of phrenic inspiratory cells was clearly different in these studies and could underlie the different occurrence (Viala et al., 1979; Schomburg et al., 2003) or absence (present study) of locomotor-related rhythmicity in spinal inspiratory neurons.

In our study, single-unit recordings revealed that all spinal expiratory cells depolarized rhythmically in time with fictive locomotion, indicating for the first time in the neonatal rat that synaptic connectivity exists between lumbar locomotor and spinal expiratory circuitry. Our data are therefore consistent with, and add to, a number of previous studies showing that axial musculature, which drives the expiratory phase of breathing at rest in mammals (Koterba et al., 1988; De Troyer et al., 1990; Deban and Carrier, 2002), is also somehow engaged in locomotion (Grillner et al., 1978; Puckree et al., 1998; Deban and Carrier, 2002; Reilly et al., 2009). For instance, the activity in nerves supplying abdominal muscles displays left/right alternation during fictive locomotion in spinalized and paralyzed cats (Koehler et al., 1984; Schomburg et al., 2003), and this predominant rhythmic pattern was reported to be highly correlated with hindlimb flexor activity (Koehler et al., 1984). Similarly, we show here that rhyth-

mic, locomotor-related depolarizations in expiratory neurons occur exclusively in phase with locomotor bursts in the ipsilateral L1-L2 ventral roots, which predominately carry hindlimb flexor motor axons to the pelvic girdle region (Kjaerulff and Kiehn, 1996). This "flexor-type" influence of the lumbar locomotor generator on expiratory neurons that control ventral trunk musculature could produce spine bending, resulting in a forward displacement of the pelvis. This in turn would assist in flexing the trunk during locomotion and facilitate respiratory exhalation. potential.
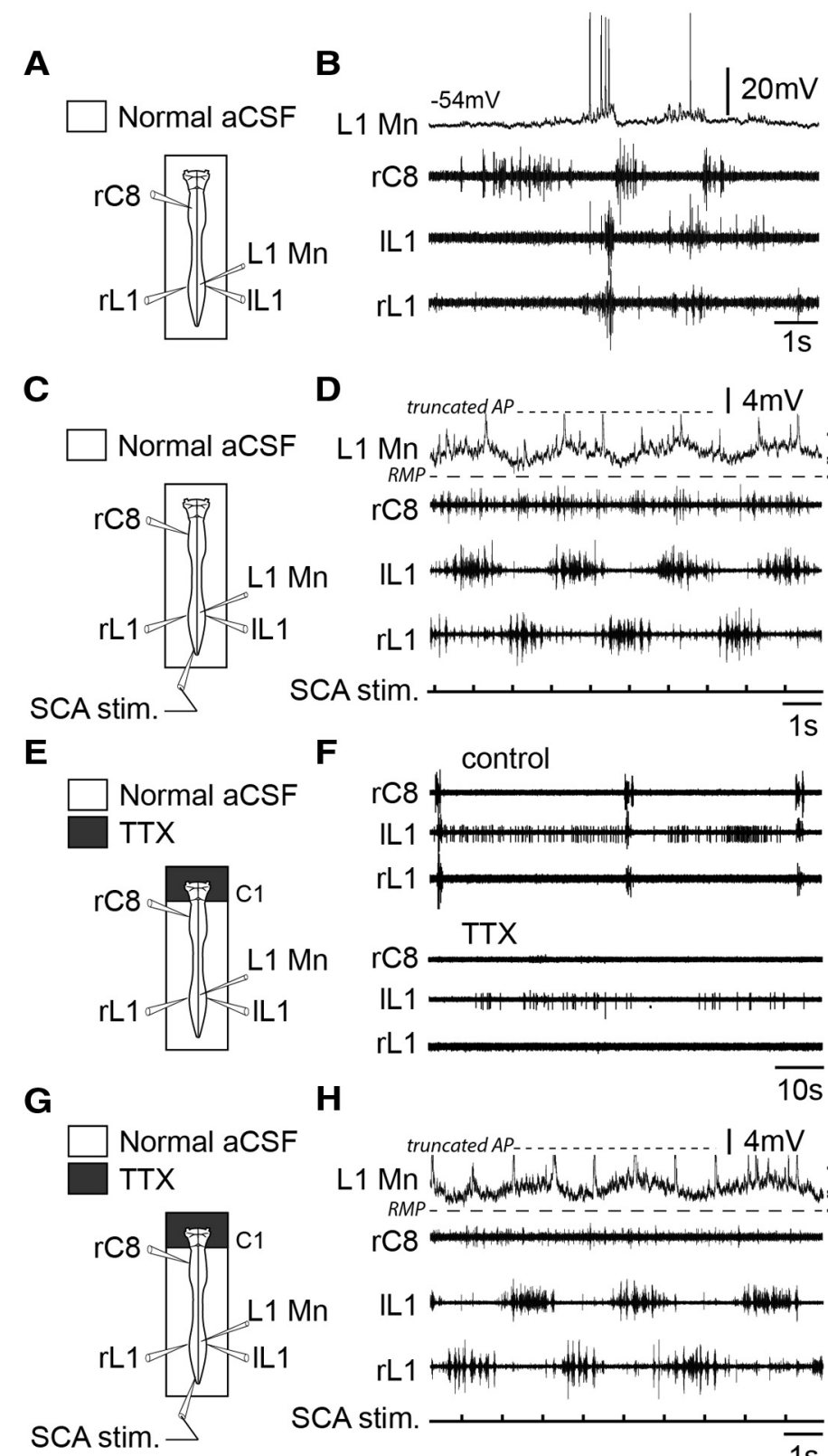

Figure 6. Locomotor generator-driven membrane oscillations of lumbar expiratory motoneurons are mediated by propriospinal pathways. $A, C, E, G$, Schematics of the experimental procedures. $\boldsymbol{B}, \boldsymbol{D}$, Rhythmic activity of a lumbar expiratory motoneuron (L1 $\mathrm{Mn}$ ), and in (8 (inspiratory-like) and left (I) and right ( $\mathrm{r}$ ) L1 (expiratory-like) ventral roots under control saline conditions ( $\boldsymbol{B}$ ), and during tonic electrical stimulation (30 pulses, $1 \mathrm{~Hz}, 0.5-1 \mathrm{~V}$ ) of sacrocaudal dorsal root afferents (SCA stim, $\boldsymbol{D}$ ). $\boldsymbol{F}$, Raw spontaneous respiratory activity in $C 8$ and bilateral L1 ventral roots under control saline conditions (top) and after application of TTX (0.5 $\mu \mathrm{M})$ to the brainstem (bottom). Note that under TTX treatment, spinal respiratory bursting was no longer produced. $\boldsymbol{H}$, Locomotor-related membrane potential oscillations in an L1 expiratory motoneuron persisted during SCA stim, while brainstem circuitry was held silent under TTX. Recordings in $\boldsymbol{B}, \boldsymbol{D}, \boldsymbol{F}$, and $\boldsymbol{H}$ are from the same preparation. AP, Action potential; RMP, resting membrane
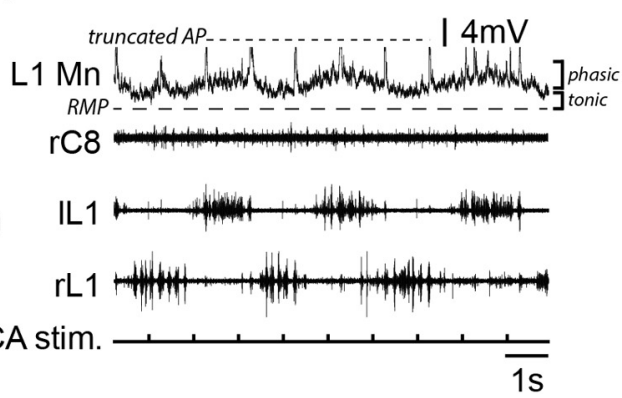


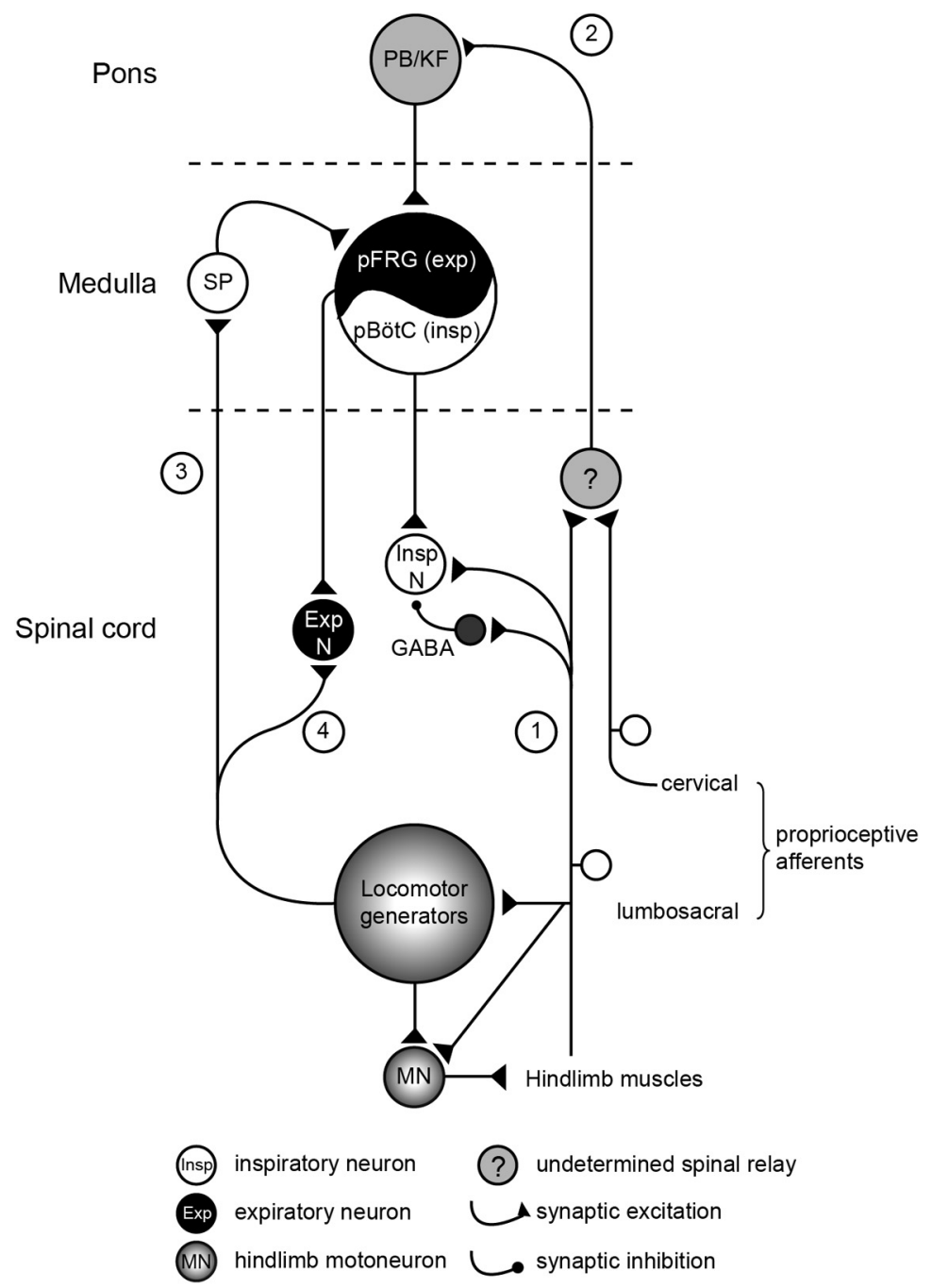

Figure 7. Summary diagram of potential sensory-motor pathways involved in the integrated locomotor-respiratory function of quadrupedal mammals. See text for further explanations. 1, Pathway 1 from Morin and Viala (2002); 2, Pathway 2 from Giraudin et al. (2012); 3, Pathway 3 from Le Gal et al. (2014b); 4, Pathway 4 from the present study.

abdominal muscle efferents engaged in both breathing and locomotor function simultaneously (Deban and Carrier, 2002). Presumably, the remaining spinal expiratory cells that express a subthreshold locomotor-related drive constitute an auxiliary motor pool that is recruited when locomotion becomes stronger. In this condition, the locomotor efference copy influence becomes correspondingly stronger, and the number of activated spinal expiratory neurons is increased to reinforce exhalation.

\section{A dual-component locomotor drive to spinal expiratory neurons}

As mentioned above, in control conditions during respiratory rhythmogenesis, thoracolumbar neurons express an expiratory-type pattern. During coincident pharmacological or electrical activation of the locomotor rhythm-generating networks, these neuronal populations also receive a central locomotor drive potential that relies exclusively on propriospinal pathways. This finding is consistent with those of previous studies showing that the spinal cord, when isolated from its supraspinal control and peripheral sensory feedback, is capable of generating locomotor-related bursts in different types of spinal respiratory neurons during fictive locomotion (Koehler et al., 1984; Viala, 1986; Schomburg et al., 2003). Interest- ingly, this locomotor influence consists of dual tonic and phasic components that are identical in shape (duration and magnitude) to those received by actual locomotor motoneurons during fictive walking patterns (Cazalets et al., 1996; Bertrand and Cazalets, 2002). These striking similarities thus argue in favor of a common origin of the locomotorrelated drive, namely the spinal locomotor rhythm generator itself. The tonic component results in a sustained depolarization of neurons throughout the locomotor episode, whereas the rhythmic phasic component is invariably phase locked, with locomotor burst activity recorded in lumbar segments. The presence of such a dual-component drive has also been observed in locomotortype motoneurons in the Xenopus embryo during swimming (Soffe and Roberts, 1982; Dale and Roberts, 1985; Tunstall and Roberts, 1994), with the tonic "slow" and the phasic "fast" depolarizing components being mediated by NMDA and kainate/quisqualate receptors, respectively. As in Xenopus spinal neurons, it is likely that, during locomotion in the neonatal rat, the tonic component provides a sustained depolarizing background level that increases the excitability of spinal expiratory neurons. This sustained depolarizing input would in turn prime thoracolumbar expiratory neurons to the coincident phasic component generated by hindlimb locomotor networks, thereby ensuring their preferential response to the locomotor drive during functional locomotor-ventilatory coordination. As mentioned above, the presence of this locomotor-related drive in spinal expiratory cells could serve to minimize the biomechanical conflicts between the locomotor and respiratory functions of the trunk musculature (Bramble and Carrier, 1983; Young et al., 1992), and to facilitate exhalation during faster locomotion.

\section{Sensory-motor pathways involved in mammalian locomotor-respiratory coordination}

Due to the tissue isolation procedure and the developmental stage used, it is widely accepted that motor output patterns generated in vitro from neonatal experimental preparations differ from the adult motor patterns produced in vivo (Smith and Feldman, 1987). With this caveat in mind, nevertheless, the isolated brainstem-spinal cord preparation from newborn animals has allowed major progress to be made in understanding the operation of the central neural networks responsible for respiration (for review, see Onimaru, 1995; Ramirez and Viemari, 2005; Feldman and Del Negro, 2006; Greer, 2012; Johnson et al., 2012; Feldman et al., 2013; Smith et al., 2013) and locomotion (Whelan, 2003; Kiehn et al., 2008; Vinay and Jean-Xavier, 2008; Brownstone and Bui, 2010; Kiehn and Dougherty, 2013), and their interconnectivity (Morin and Viala, 2002; Giraudin et al., 
2008, 2012; Le Gal et al., 2014b). On the basis of our previous and present in vitro findings, we propose the involvement of specific neural substrates that could subserve locomotor-respiratory coordination in the freely moving animal (Fig. 7). During locomotion, sensory inputs from somatic proprioceptive afferents activated by limb muscle contractions are responsible for entraining ongoing respiratory rhythmicity (Fig. 7, pathways 1 and 2; Morin and Viala, 2002). This ascending excitatory signal is first relayed synaptically in the rostral spinal cord and then conveyed to the parabrachial/Kölliker-Fuse nuclei in the brainstem pontine region, from where it is transmitted to the medullary respiratory networks (Fig. 7, pathway 2; Giraudin et al., 2012). The ability of forelimb and hindlimb somatic afferent inputs to entrain the respiratory rhythm at birth is the mechanism by which locomotor-respiratory coupling would be achieved in quadrupeds. In addition, afferent inputs have direct access to inspiratory phrenic motoneurons, which receive a characteristic sequence of excitatory and inhibitory synaptic inputs during the activation of limb proprioceptive afferents (Fig. 7, pathway 1). The resulting change in cellular excitability may serve to prepare spinal inspiratory neurons to respond adequately to the medullary respiratory drive entrained by limb sensory afferent activation (Morin and Viala, 2002). In parallel, the hindlimb locomotor pattern generators themselves participate in increasing respiratory network rhythmicity during episodes of locomotion (Fig. 7, pathway 3; Le Gal et al., 2014b). This influence is mediated by an ascending excitatory signal that is conveyed to the \& parafacial respiratory group ( $\mathrm{pFRG)}$ via the activation of a brainstem substance P-releasing pathway. Consequently, during locomotion, pFRG/preinspiratory neurons are tonically depolarized and could be responsible for the locomotion-induced respiratory acceleration. Finally, in the present study, we further show that the hindlimb locomotor rhythm generators, when active, have the ability to directly modulate the excitability of spinal expiratory motoneurons and interneurons (Fig. 7, pathway 4). This locomotor-related drive in spinal expiratory cells could serve to facilitate respiratory exhalation during locomotion. However, whether their forelimb counterparts are similarly able to influence the excitability of brainstem and/or spinal respiratory neurons during quadrupedal locomotion remains unknown.

\section{References}

Bertrand S, Cazalets JR (2002) The respective contribution of lumbar segments to the generation of locomotion in the isolated spinal cord of newborn rat. Eur J Neurosci 16:1741-1750. CrossRef Medline

Beyeler A, Métais C, Combes D, Simmers J, Le Ray D (2008) Metamorphosis-induced changes in the coupling of spinal thoracolumbar motor outputs during swimming in Xenopus laevis. J Neurophysiol 100:1372-1383. CrossRef Medline

Bramble DM, Carrier DR (1983) Running and breathing in mammals. Science 219:251-256. CrossRef Medline

Brownstone RM, Bui TV (2010) Spinal interneurons providing input to the final common path during locomotion. Prog Brain Res 187:81-95. CrossRef Medline

Cazalets JR, Borde M, Clarac F (1996) The synaptic drive from the spinal locomotor network to motoneurons in the newborn rat. J Neurosci 16: 298-306. Medline

Cohen MI (1979) Neurogenesis of respiratory rhythm in the mammal. Physiol Rev 59:1105-1173. Medline

Combes D, Le Ray D, Lambert FM, Simmers J, Straka H (2008) An intrinsic feed-forward mechanism for vertebrate gaze stabilization. Curr Biol 18: R241-R243. CrossRef Medline

Dale N, Roberts A (1985) Dual-component amino-acid-mediated synaptic potentials: excitatory drive for swimming in Xenopus embryos. J Physiol 363:35-59. CrossRef Medline

de Almeida AT, Al-Izki S, Denton ME, Kirkwood PA (2010) Patterns of expiratory and inspiratory activation for thoracic motoneurones in the anaesthetized and the decerebrate rat. J Physiol 588:2707-2729. CrossRef Medline

Deban SM, Carrier DR (2002) Hypaxial muscle activity during running and breathing in dogs. J Exp Biol 205:1953-1967. Medline

De Troyer A, Estenne M, Ninane V, Van Gansbeke D, Gorini M (1990) Transversus abdominis muscle function in humans. J Appl Physiol 68: 1010-1016. Medline

Etlin A, Finkel E, Mor Y, O’Donovan MJ, Anglister L, Lev-Tov A (2013) Characterization of sacral interneurons that mediate activation of locomotor pattern generators by sacrocaudal afferent input. J Neurosci 33: 734-747. CrossRef Medline

Ezure K, Tanaka I (1997) Convergence of central respiratory and locomotor rhythms onto single neurons of the lateral reticular nucleus. Exp Brain Res 113:230-242. CrossRef Medline

Falgairolle M, Cazalets JR (2007) Metachronal coupling between spinal neuronal networks during locomotor activity in newborn rat. J Physiol 580:87-102. CrossRef Medline

Feldman JL, Del Negro CA (2006) Looking for inspiration: new perspectives on respiratory rhythm. Nat Rev Neurosci 7:232-242. CrossRef Medline

Feldman JL, Del Negro CA, Gray PA (2013) Understanding the rhythm of breathing: so near, yet so far. Annu Rev Physiol 75:423-452. CrossRef Medline

Giraudin A, Cabirol-Pol MJ, Simmers J, Morin D (2008) Intercostal and abdominal respiratory motoneurons in the neonatal rat spinal cord: spatiotemporal organization and responses to limb afferent stimulation. J Neurophysiol 99:2626-2640. CrossRef Medline

Giraudin A, Le Bon-Jégo M, Cabirol MJ, Simmers J, Morin D (2012) Spinal and pontine relay pathways mediating respiratory rhythm entrainment by limb proprioceptive inputs in the neonatal rat. J Neurosci 32: 11841-11853. CrossRef Medline

Greer JJ (2012) Control of breathing activity in the fetus and newborn. Compr Physiol 2:1873-1888. CrossRef Medline

Grillner S, Nilsson J, Thorstensson A (1978) Intra-abdominal pressure changes during natural movements in man. Acta Physiol Scand 103: 275-283. CrossRef Medline

Hilaire G, Monteau R, Errchidi S (1989) Possible modulation of the medullary respiratory rhythm generator by the noradrenergic $\mathrm{A} 5$ area: an in vitro study in the newborn rat. Brain Res 485:325-332. CrossRef Medline

Iizuka M (1999) Intercostal expiratory activity in an in vitro brainstemspinal cord-rib preparation from the neonatal rat. J Physiol 520:293-302. CrossRef Medline

Iizuka M (2004) Rostrocaudal distribution of spinal respiratory motor activity in an in vitro neonatal rat preparation. Neurosci Res 50:263-269. CrossRef Medline

Iizuka M (2009) Abdominal expiratory muscle activity in anesthetized vagotomized neonatal rats. J Physiol Sci 59:157-163. CrossRef Medline

Iizuka M (2011) Respiration-related control of abdominal motoneurons. Respir Physiol Neurobiol 179:80-88. CrossRef Medline

Janczewski WA, Onimaru H, Homma I, Feldman JL (2002) Opioid-resistant respiratory pathway from the preinspiratory neurones to abdominal muscles: in vivo and in vitro study in the newborn rat. J Physiol 545:10171026. CrossRef Medline

Johnson SM, Turner SM, Huxtable AG, Ben-Mabrouk F (2012) Isolated in vitro brainstem-spinal cord preparations remain important tools in respiratory neurobiology. Respir Physiol Neurobiol 180:1-7. CrossRef Medline

Juvin L, Simmers J, Morin D (2005) Propriospinal circuitry underlying interlimb coordination in mammalian quadrupedal locomotion. J Neurosci 25:6025-6035. CrossRef Medline

Juvin L, Le Gal JP, Simmers J, Morin D (2012) Cervicolumbar coordination in mammalian quadrupedal locomotion: role of spinal thoracic circuitry and limb sensory inputs. J Neurosci 32:953-965. CrossRef Medline

Kiehn O, Dougherty K (2013) Locomotion: circuits and physiology. In: Neuroscience in the 21st century: from basic to clinical (Pfaff DW, ed), pp 1209-1236. New York: Springer.

Kiehn O, Quinlan KA, Restrepo CE, Lundfald L, Borgius L, Talpalar AE, Endo $\mathrm{T}$ (2008) Excitatory components of the mammalian locomotor CPG. Brain Res Rev 57:56-63. CrossRef Medline

Kjaerulff O, Kiehn O (1996) Distribution of networks generating and coordinating locomotor activity in the neonatal rat spinal cord in vitro: a lesion study. J Neurosci 16:5777-5794. Medline 
Koehler WJ, Schomburg ED, Steffens H (1984) Phasic modulation of trunk muscle efferents during fictive spinal locomotion in cats. J Physiol 353: 187-197. CrossRef Medline

Koterba AM, Kosch PC, Beech J, Whitlock T (1988) Breathing strategy of the adult horse (Equus caballus) at rest. J Appl Physiol 64:337-346. Medline

Lambert FM, Combes D, Simmers J, Straka H (2012) Gaze stabilization by efference copy signaling without sensory feedback during vertebrate locomotion. Curr Biol 22:1649-1658. CrossRef Medline

Le Gal JP, Juvin L, Morin D (2014a) Expiratory motoneurones: bifunctional respiratory and locomotor spinal neurons? Paper presented at The International Motoneuron Meeting, Halifax, NS, Canada, June.

Le Gal JP, Juvin L, Cardoit L, Thoby-Brisson M, Morin D (2014b) Remote control of respiratory neural network by spinal locomotor generators. PLoS One 9:e89670. CrossRef Medline

Lev-Tov A, Delvolvé I, Kremer E (2000) Sacrocaudal afferents induce rhythmic efferent bursting in isolated spinal cords of neonatal rats. J Neurophysiol 83:888-894. Medline

Morin D, Viala D (2002) Coordinations of locomotor and respiratory rhythms in vitro are critically dependent on hindlimb sensory inputs. J Neurosci 22:4756-4765. Medline

Morin D, Bonnot A, Ballion B, Viala D (2000) Alpha1-adrenergic receptorinduced slow rhythmicity in nonrespiratory cervical motoneurons of neonatal rat spinal cord. Eur J Neurosci 12:2950-2966. CrossRef Medline

Murakoshi T, Suzue T, Tamai S (1985) A pharmacological study on respiratory rhythm in theisolated brainstem-spinal cord preparation of the newborn rat. Br J Pharmacol 86:95-104. CrossRef Medline

Onimaru H (1995) Studies of the respiratory center using isolated brainstem-spinal cord preparations. Neurosci Res 21:183-190. CrossRef Medline

Panaitescu B, Ruangkittisakul A, Ballanyi K (2010) Depression by Ca2 ${ }^{+}$and stimulation by $\mathrm{K}^{+}$of fictive inspiratory rhythm in newborn rat brainstem slices. Adv Exp Med Biol 669:91-95. CrossRef Medline

Puckree T, Cerny F, Bishop B (1998) Abdominal motor unit activity during respiratory and nonrespiratory tasks. J Appl Physiol 84:1707-1715. Medline

Ramirez JM, Viemari JC (2005) Determinants of inspiratory activity. Respir Physiol Neurobiol 147:145-157. CrossRef Medline

Reilly SM, McElroy EJ, White TD (2009) Abdominal muscle function in ventilation and locomotion in new world opossums and basal eutherians: breathing and running with and without epipubic bones. J Morphol 270: 1014-1028. CrossRef Medline

Ruangkittisakul A, Secchia L, Bornes TD, Palathinkal DM, Ballanyi K (2007) Dependence on extracellular $\mathrm{Ca} 2{ }^{+} / \mathrm{K}^{+}$antagonism of inspiratory centre rhythms in slices and en bloc preparations of newborn rat brainstem. J Physiol 584:489-508. CrossRef Medline

Saji M, Miura M (1990) Thoracic expiratory motor neurons of the rat: lo- calization and sites of origin of their premotor neurons. Brain Res 507: 247-253. CrossRef Medline

Schomburg ED, Steffens H, Dembowsky K (2003) Rhythmic phrenic, intercostal and sympathetic activity in relation to limb and trunk motor activity in spinal cats. Neurosci Res 46:229-240. CrossRef Medline

Smith JC, Feldman JL (1987) In vitro brainstem-spinal cord preparations for study motor systems for mammalian respiration and locomotion. J Neurosci Methods 21:321-333. CrossRef Medline

Smith JC, Greer JJ, Liu G, Feldman JL (1990) Neural mechanisms generating respiratory pattern in mammalian brain stem-spinal cord in vitro. I. Spatio-temporal patterns of motor and medullary neuron activity. J Neurophysiol 64:1149-1169. Medline

Smith JC, Abdala AP, Borgmann A, Rybak IA, Paton JF (2013) Brainstem respiratory networks: building blocks and microcircuits. Trends Neurosci 36:152-162. CrossRef Medline

Soffe SR, Roberts A (1982) Tonic and phasic synaptic input to spinal cord motoneurons during fictive locomotion in frog embryos. J Neurophysiol 48:1279-1288. Medline

Suzue T (1984) Respiratory rhythm generation in the in vitro brain stemspinal cord preparation of the neonatal rat. J Physiol 354:173-183. CrossRef Medline

Tunstall MJ, Roberts A (1994) A longitudinal gradient of synaptic drive in the spinal cord of Xenopus embryos and its role in co-ordination of swimming. J Physiol 474:393-405. CrossRef Medline

Viala D (1986) Evidence for direct reciprocal interactions between the central rhythm generators for spinal "respiratory" and locomotor activities in the rabbit. Exp Brain Res 63:225-232. Medline

Viala D, Vidal C, Freton E (1979) Coordinated rhythmic bursting in respiratory and locomotor muscle nerves in the spinal rabbit. Neurosci Lett 11:155-159. CrossRef Medline

Viala D, Persegol L, Palisses R (1987) Relationship between phrenic and hindlimb extensor activities during fictive locomotion. Neurosci Lett 74: 49-52. CrossRef Medline

Vinay L, Jean-Xavier C (2008) Plasticity of spinal cord locomotor networks and contribution of cation-chloride cotransporters. Brain Res Rev 57: 103-110. CrossRef Medline

von Uckermann G, Le Ray D, Combes D, Straka H, Simmers J (2013) Spinal efference copy signaling and gaze stabilization during locomotion in juvenile Xenopus frogs. J Neurosci 33:4253-4264. CrossRef Medline

Whelan PJ (2003) Developmental aspects of spinal locomotor function: insights from using the in vitro mouse spinal cord preparation. J Physiol 553:695-706. CrossRef Medline

Whelan P, Bonnot A, O'Donovan MJ (2000) Properties of rhythmic activity generated by the isolated spinal cord of the neonatal mouse. J Neurophysiol 84:2821-2833. Medline

Young IS, Warren RD, Altringham JD (1992) Some properties of the mammalian locomotory and respiratory systems in relation to body mass. J Exp Biol 164:283-294. Medline 